\title{
Regional carbon dioxide and energy fluxes from airborne observations using flight-path segmentation based on landscape characteristics
}

\author{
O. S. Vellinga ${ }^{1,3}$, B. Gioli ${ }^{2}$, J. A. Elbers ${ }^{1}$, A. A. M. Holtslag ${ }^{3}$, P. Kabat ${ }^{1}$, and R. W. A. Hutjes ${ }^{1}$ \\ ${ }^{1}$ Wageningen University, Earth-System Science \& Climate-Change Group, Wageningen, The Netherlands \\ ${ }^{2}$ Institute of Biometeorology, IBIMET-CNR, Florence, Italy \\ ${ }^{3}$ Wageningen University, Meteorology \& Air-Quality Group, Wageningen, The Netherlands
}

Received: 1 October 2009 - Published in Biogeosciences Discuss.: 11 November 2009

Revised: 19 March 2010 - Accepted: 25 March 2010 - Published: 21 April 2010

\begin{abstract}
This paper presents an analysis of regional fluxes obtained with a small aircraft over heterogeneous terrain in the south-west of France, during the large scale field experiment CERES'07. We use a method combining variable flight-path segmentation with basic airborne footprint analysis. The segmentation is based on topography, land use and soil type, using a.o. satellite imagery and digital maps. The segments are delineated using an average footprint length, based on all flights, and segment lengths, which are variable in space but not in time. The method results in segment averaged carbon and energy fluxes, which are shown to be representative of regional fluxes. Our analysis is focussed on carbon dioxide, heat and evaporative fluxes around solar noon. We will show that spatial and seasonal variations in the fluxes can be linked to the underlying landscape. In addition, a comparison between the airborne data and ground flux data is made to support our results. However, due to the incompleteness of ground data for some predominant vegetation types (even in such a data dense context), upscaling of ground data to regional fluxes was not possible. Without the comparison, we are still able to demonstrate that aircraft can provide direct and meaningful estimates of regional fluxes of energy and carbon dioxide.
\end{abstract}

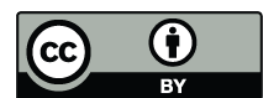

Correspondence to: O. S. Vellinga (olaf.vellinga@wur.nl)

\section{Introduction}

Global and recently regional atmospheric transport models are often used with inverse methods to quantify the carbon balance from atmospheric observations. Powerful at global to continental scales, observational density and methodological progress have lead to useful higher resolution applications (Peters et al., 2007). At the other end of the scale, in the past decades, the flux community (e.g. Ameriflux and CarboEurope-IP) has built up extensive networks of flux sites around the world. These networks have been the main source for understanding the local-scale processes of the carbon cycle, and process-based models, often in combination with statistical and/or GIS methods, to scale up to regional and global scale (e.g. Denning et al., 1999). However, aggregation of processes from bottom-up to larger scales also has its limitations, due to the still low density of flux networks in comparison to the heterogeneity found in the field. The regional scale has been considered as the missing scale between these global and local approaches, respectively. Regional budgets and processes might be resolved by obtaining flux data at strategic periods during the annual cycle throughout the atmospheric boundary-layer in an area that is large enough to resolve these processes. In this respect, aircrafts are of particular interest, because they can measure an integral regional flux.

In this context, aircrafts have been involved in atmospheric research for decades. Their contribution is especially known from large field experiments as HAPEX-MOBILHY (André et al., 1986), FIFE (Sellers et al., 1988), BOREAS (Hall, 2001), COBRA (Gerbig et al., 2003), LBA-CLAIRE-98 (Andreae et al., 2001) and RECAB (e.g. Hutjes et al., 2003;

Published by Copernicus Publications on behalf of the European Geosciences Union. 
Schmitgen et al., 2004; Vila-Guerau de Arellano et al., 2004). From these experiments and others, several studies have been published first focussing on data quality (e.g. Gioli et al., 2004; Mahrt, 1998; Mann and Lenschow, 1994) and data analyses over more or less homogeneous terrain (e.g. Desjardins et al., 1992, 1994; Pérez-Landa et al., 2007). In recent years, research has shifted more to the development of methods for use in much more heterogeneous terrain, like sophisticated approaches of flux disaggregation of airborne data obtained over heterogeneous terrain (e.g. Kirby et al., 2008; Ogunjemiyo et al., 2003; Hutjes et al., 2010). Our study presents a basic analysis strategy for regional fluxes using airborne data obtained over heterogeneous terrain during a large field experiment carried out in 2007.

The field experiment, during which our data were obtained, was the CarboEurope Regional Experiment Strategy (CERES'07, Dolman et al., 2009) as part of the European 6th framework integrated project CarboEurope (http: //www.carboeurope.org/). It was similar in set-up as the previous campaign (CERES'05, Dolman et al., 2006), where flux towers, tall towers, radiosondes, and aircrafts were involved to quantify the carbon balance at regional scale in south-west of France. The experiment "planned to combine various types of ground-based carbon-cycle related measurements and atmospheric observations with remote sensing to infer a regional carbon budget" (Dolman et al., 2006). CERES'05 ran for a period of six weeks during the growing season in May and June. CERES'07 was completed in two intensive observation periods in April (IOP 1; day 108-112) and September (IOP 2; day 250-258), which both are seasonally complementary to each other. We have participated in this experiment with our small environmental research aircraft (SERA).

In this paper, we present airborne regional carbon and energy fluxes obtained with our SERA during CERES'07. We use a method of variable flight-path segmentation aiming at minimal variability within segments, while linking between segment variation to landscape-scale variations. Our focus will be on the segment-averaged turbulent fluxes of carbon dioxide, heat and water vapour. In addition, a comparison at the regional scale between the airborne data and ground flux data is made to support the results.

\section{Experimental set-up}

\subsection{Area description}

Figure 1 shows the experimental domain of CERES'07. The area under investigation $(150 \mathrm{~km} \times 250 \mathrm{~km}$; box in figure $)$ is located in the south-west of France. It stretches from the city of Toulouse in the east to the Atlantic coast in the west, and from the city of Bordeaux in the north to the Pyrenees mountains in the south. The domain can be divided into four main regions of land use. Along the whole Atlantic coastline be-

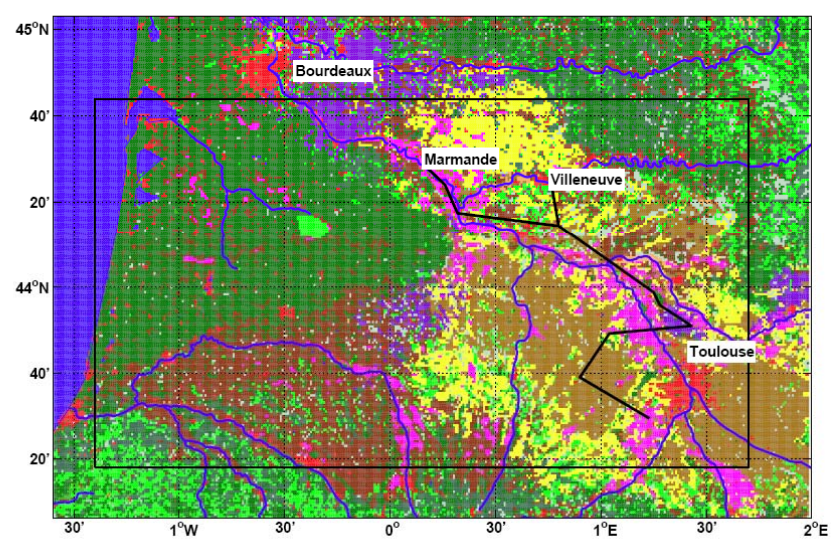

Fig. 1. Enhanced 1-km resolution CORINE 2000 land-use map of south-west of France and schematic river system with experimental domain of CERES'07 measurement campaign (box) with our two schematic flight tracks for both IOPs.

tween the Pyrenees and Bordeaux, the "Les Landes" forest area stretches halfway inland into the domain in a trianglar shape. To the south-east of Les Landes towards the Pyrenees, mainly summer crops (sunflowers, maize and vegetables) are grown in complex cultivation patterns. To the northeast of Les Landes along the river "Garonne", vineyards are the main land use. The Garonne River is the largest river running through the domain between Bordeaux and Toulouse. The remaining part to the east is used for mainly growing winter crops (winter wheat).

Our flight domain covered the eastern part of the larger CERES'07 experimental area (see Fig. 1). The terrain between the towns of Marmande (MA), Villeneuve-Sur-Lot (hereafter called Villeneuve) and Lamasquérè (LA) can be divided into three main regions (see Fig. 2): the river "Garonne" and its valley, the hills to the north-east and the geologically different hills to the south-west. The main landuse classes (see Sect. 4 for info on land-use map) in the flight domain are "Winter Crops" (WC), "Wheat/Maize" (WM), "Market Gardening" (MG), "Complex Cultivation Patterns with mainly Winter Crops" (CCP/WC), "Complex Cultivation Patterns with mainly Summer Crops" (CCP/SC) and "Mixed Forest" (FO) (see upper plot Fig. 5). Market gardening consists of small scale production of fruits, vegetables, flowers and cash crops, including greenhouses, for the consumer market. Classes CCP/WC and CCP/SC are more specific classes of the original CORINE 2000 class "complex cultivation patterns". Both classes are composed of small parcels of diverse annual crops, pasture and/or permanent crops with one predominant land-use type (SC or WC). In addition, small parcels of arable land, orchards, and city gardens are included in this category. Classes of artificial surfaces (e.g. infrastructure, airports, and urban areas) account for about $4 \%$ in this area. The predominant soil types are loam and clay, where clay largely is found in the hills, 
in some cases mixed with loam. Figure 3 shows the terrain elevation along the flight track between Marmande and Lamasquérè with main soil types and land cover classes. The figure shows that the flight track crosses the Garonne Valley three times at different locations, while crossing the river two times.

\subsection{Synoptic weather conditions}

Both intensive observation periods in April and September were dominated by clear skies with high average maximum daytime temperatures $\left(\sim 23^{\circ} \mathrm{C}\right)$ and light, variable winds $(\sim 2 \mathrm{~m} / \mathrm{s})$ with no precipitation. However, two weeks before the start of IOP 1 , about $27 \mathrm{~mm}$ of precipitation was observed at the ground sites in the area with an average maximum daytime temperature of about $14^{\circ} \mathrm{C}$, while in the same period before the start of IOP 2 , only about $4 \mathrm{~mm}$ of rain with an average maximum daytime temperature of about $22^{\circ} \mathrm{C}$ was observed.

At the start of IOP 1, a high-pressure system $(>1025 \mathrm{hPa})$ was located above western Europe with its center above south-west of Ireland and a low-pressure system $(<1005 \mathrm{hPa})$ centred above Algeria, northern Africa. Both systems were moving eastward, gradually weakening somewhat. By the end of the period, their centres were located above the Ukraine (high) and Egypt (low). Between these two larger systems, small highs and lows were developing and disappearing. Meanwhile, a new large high-pressure system was coming in from the Azores. This one developed together with the old high above Ukraine into a blockage over the whole of Europe against a newly developed large low to the west of Ireland.

The second IOP, was dominated by a stationary large highpressure system $(>1030 \mathrm{hPa})$ above western Europe again with its center above south-west of Ireland. During the second half of this period, a low pressure-system $(<1015 \mathrm{hPa})$ was moving in from northern Africa. During the IOP, a new high developed above the Azores. By the end of IOP 2, the low was strong enough to divide the high into two regions with one large high above the Atlantic to the west of Portugal and some small highs above central and eastern Europe. The low was now stretching out over most part of France with its center above the coastline of Algeria.

\subsection{Instrumentation}

Eight ground measurement sites, two tall towers, two radiosonde sites, and five aircraft were involved in the field experiment. Two of the aircraft were almost identical: one operated by the Institute of Biometeorology of the Italian National Research Council (IBIMET-CNR, Italy) and our own aircraft. It is a Sky Arrow 650 ERA with a Mobile Flux Platform (MFP) installed, which is built by Iniziative Industriali Italiane S.p.A. (Rome, Italy) in collaboration with Terrasystem s.r.l. (Viterbo, Italy). The MFP is a collection of instru-

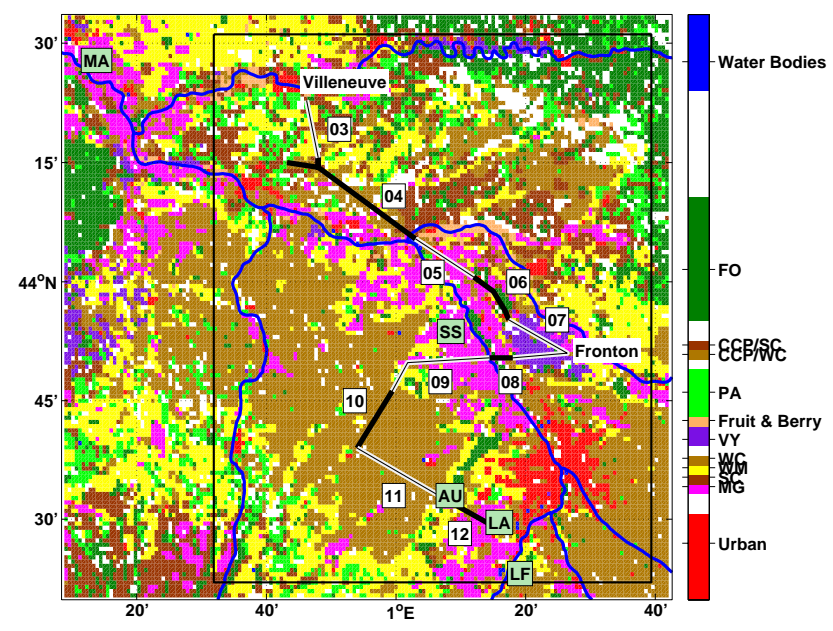

Fig. 2. Flight domain with two schematic flight tracks divided into 12 segments $(\mathrm{B} / \mathrm{W})$ and ground flux sites (2-character labels; see text for abbreviations) in the direct vicinity. Rectangular box depicts the extracted domain area of land use for reference with regard to land-use distribution for segment 3 to 12 (see Fig.5).

ments built around the Best Atmospheric Turbulence (BAT) probe, developed by the National Oceanic and Atmospheric Administration (NOAA, USA), in conjunction with Airborne Research Australia (ARA, Hacker and Crawford, 1999). Our MFP-system differs from the Italian aircraft (see Gioli et al., 2006, for their type of instruments) only in the temperature probe (by Terrasystem s.r.l.), the GPS/INS (C-Migits ${ }^{\mathrm{TM}}$ III by Systron Donner), the net radiation instrument (NR Lite by Kipp \& Zonen) and the absence of a dew-point temperature probe. The system is a proven design for airborne measurements of fluxes of carbon dioxide, momentum and heat (Dumas et al., 2001; Gioli et al., 2004). Of the eight ground sites, five were located close to our flight track as shown in Fig. 2: station 'Marmande' (MA; $44^{\circ} 28^{\prime} \mathrm{N}, 00^{\circ} 12^{\prime} \mathrm{E}$ ) maintained by Alterra; stations "Saint Sardos" (SS; $43^{\circ} 54^{\prime} \mathrm{N}, 01^{\circ} 07^{\prime} \mathrm{E}$ ) and "Le Fauga" (LF; $43^{\circ} 23^{\prime} \mathrm{N}, 01^{\circ} 18^{\prime} \mathrm{E}$ ) ran by Centre National de Recherches Meteorologiques (CNRM, France); and stations "Auradé" (AU; $43^{\circ} 33^{\prime} \mathrm{N}, 01^{\circ} 07^{\prime} \mathrm{E}$ ) and 'Lamasquérè' (LA; $43^{\circ} 30^{\prime} \mathrm{N}, 01^{\circ} 14^{\prime} \mathrm{E}$ ) operated by Centre d'Etudes Spatiales de la BIOsphère (CESBIO, France).

\section{Flight tracks}

During IOP 1, we started our flights from the airport of Villeneuve and, during IOP 2, from the airport of Marmande (see Fig. 1). Given the different starting locations, the flight tracks in both IOPs were largely the same, except for the first part. The flight tracks were planned in such a manner that the aircraft flew directly over the ground sites with the intention to validate the airborne data. Several restricted airspaces in the flight domain, additionally, determined the shape of our flight tracks. During IOP 1, four short $(84 \mathrm{~km})$ 


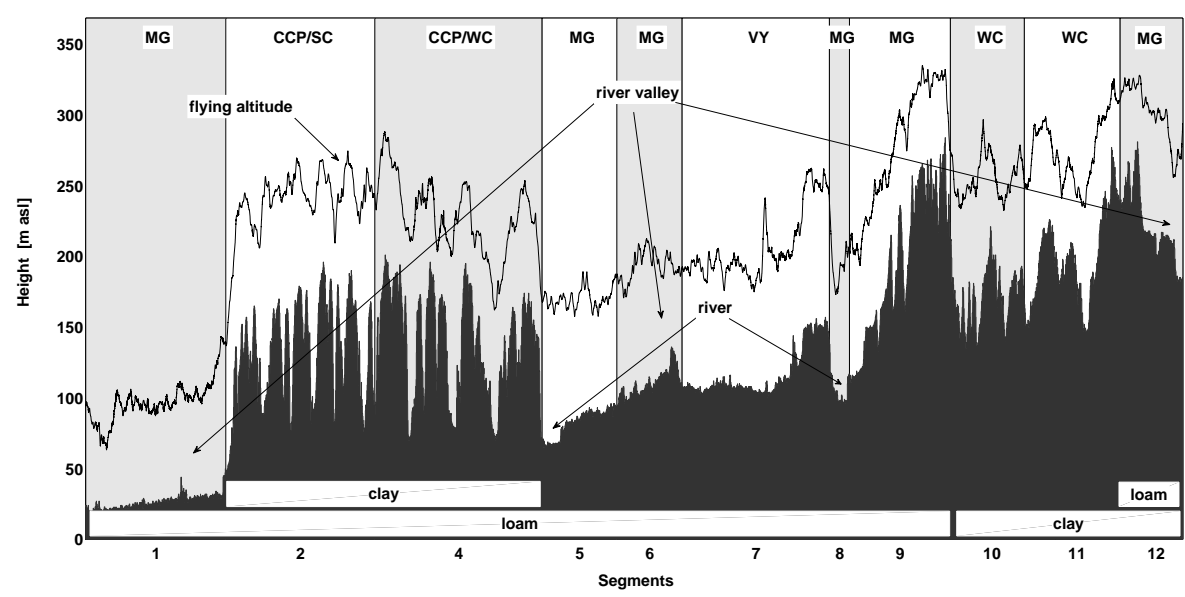

Fig. 3. Terrain elevation along flight track and an example of the flying altitude from a flight between Marmande to Lamasquérè (left to right) at CERES'07, including segments with labels of main land-use classes (2-character labels; see text for abbreviations) and main soil type (bars).

and five long $(173 \mathrm{~km})$ return flights were carried out, i.e. the aircraft made, respectively, eight and ten passes along the flight tracks. The long transect flights covered the full area between Villeneuve and Lamasquérè (LA), the short flights only half the distance till Fronton (see Fig. 2). Similar flights ( 8 passes; $218 \mathrm{~km}$ ) were carried out during IOP 2 , only now starting at Marmande. Table 1 summarizes the different transect flights carried out during CERES'07. Figure 1 shows the location of the two flight tracks within the CERES domain.

Flights were performed at low air speeds $(\approx 37 \mathrm{~m} / \mathrm{s})$ to maximize the spatial resolution of our raw data. In addition, the aircraft was flown as level as possible, where its bank was not allowed to exceed 20 degrees. Bends or curves in the flight track (e.g. segment 7 in Fig. 2) with steeper bank were excluded from flux calculations. We flew at low, constant altitude above ground level $(\approx 82 \pm 14 \mathrm{~m}$ a.g.l. $)$, following the topography to the best abilities of the pilot (see also Fig. 3). The flying altitude was chosen such as to minimize the footprint of our measurements and also to stay well within the surface layer. From vertical profiles carried out during each transect flight, the boundary-layer depth was determined at around $1.0-1.5 \mathrm{~km}$ for all flight periods used in this study (between 11:50-14:00 UTC, see later on). This is supported by radiosonde observations in the area (Sarrat et al., 2009a). The flight level is, therefore, within the surface layer for all the flights evaluated in this study. As such, the observed fluxes are expected to be close to the surface fluxes.

Possibly, a more useful concept in this context is the "blending height" (Claussen, 1990). Since we are interested in average fluxes for the segments, our flight level was chosen to be above the so-called "local" blending height, i.e. the fluxes from individual fields are no longer discernible. At the same time, we aimed it to be below the so-called "regional" blending height, ensuring that the flux differences between the segments generally do not become significantly convo-
Table 1. Performed measurement flights during IOP 1 (1822 April) and IOP 2 (7-14 September) at CERES'07 (FR = Fronton; LA = Lamasquérè; MA = Marmande; VI = Villeneuve /s Lot $)$.

\begin{tabular}{lccc}
\hline & \multicolumn{2}{c}{ IOP 1} & IOP 2 \\
\hline Transect & short & long & long \\
\hline Segments & $3-7$ & $3-12$ & $1-12$ \\
Passes & 8 & 10 & 8 \\
Start Track & VI & VI & MA \\
End Track & FR & LA & LA \\
Distance (km) & 84 & 173 & 218 \\
Time Period (UTC) & $07: 30-09: 45$ & $11: 45-17: 30$ & $07: 30-14: 45$ \\
Height (m a.g.l.) & $\approx 78 \pm 15$ & $\approx 79 \pm 14$ & $\approx 90 \pm 14$ \\
Ground Speed (m/s) & $\approx 38$ & $\approx 38$ & $\approx 37$ \\
\hline
\end{tabular}

luted. An in-depth discussion of these concepts is beyond the scope of this paper, but we demonstrate in the supplement to this paper (see http://www.biogeosciences.net/7/1307/2010/ bg-7-1307-2010-supplement.pdf) that we performed our airborne measurements above the local blending height. Based on the model by Wood and Mason (1991), we calculated blending heights for each segment. As field sizes are generally small in our domain, blending heights on average are between 20-30 m, though incidentally, it reaches up to about $80 \mathrm{~m}$. This obviously shows that, while we have generally been flying at $82 \mathrm{~m}(\sigma=14 \mathrm{~m})$ above the ground, this is above the local blending height. On the other hand, we have been flying below the regional blending height, which is at least an order of magnitude higher.

Another criterion for choosing a proper flight level for making surface flux-measurements is the wish to minimize flux divergence between the surface and measuring height. Obviously, this could be conflicting with the need to stay above the local blending height. Here, an in-depth 
analysis of flux-divergence effects on our data is beyond the scope of the paper, but we made a first-order analysis based on dedicated observations of divergence obtained in collaboration with the Italian airborne team (see supplement at http://www.biogeosciences.net/7/1307/2010/ bg-7-1307-2010-supplement.pdf). Results from this experiment show that, when dealing with flux measurements taken at a height of approx. $82 \mathrm{~m}$ from the ground, a possible underestimation of surface fluxes may occur. This is in part caused by vertical flux divergence, and in part by flux-loss associated to airborne eddy covariance or transient effects. The latter may be more important than the divergence term in deep midday convective boundary-layers (CBLs), also because the CBL that was observed during this flux-divergence experiment, was about $600 \mathrm{~m}$ maximum depth, which is lower than the CBL-depths observed during other days of the same period. Therefore, we did not attempt to correct for possible flux divergence, but we need to take into account that our airborne regional fluxes might be somewhat underestimated.

\section{Method}

To process the raw data, we developed a MATLAB® toolbox with which the three main processing steps can be performed. The toolbox is mainly based on the Unix program MakePOD (Eckman et al., 1999) developed by the NOAA Air Resources Laboratory (ARL-NOAA, USA) and additional code written by B. Gioli of IBIMET-CNR. In the first processing step, data is de-spiked and gap-filled. The data from our MFP hardly contain any spikes due to stable electronics and good weather conditions during both IOPs (see Sect. 2.2). Only the (thinwire thermocouple-based) temperature signal was occasionally distorted by radio communication between the pilot and air-traffic control. The distorted parts were removed and, where necessary, gap-filled by lineair interpolation. In the second processing step, 3-D aircraft movements are mathematically compensated for and the signals of the pressure anemometer are converted to wind direction and wind speed. This procedure is specific to our MFP instrumental set-up and airframe configuration. In the final processing steps, data are cross-correlated and spatially averaged and fluxes are calculated. Outliers in the flux data were removed using a physical range filter of 0 to $800 \mathrm{~W} / \mathrm{m}^{2}$ for sensible heat $(H)$ and latent heat $(\lambda E)$ flux, and -50 to $50 \mu \mathrm{mol} / \mathrm{m}^{2} / \mathrm{s}$ for carbondioxide fluxes $\left(f \mathrm{CO}_{2}\right)$. If $H$ and/or $\lambda E$ was discarded, then $f \mathrm{CO}_{2}$ was discarded as well.

Contrary to tower measurements, fluxes based on aircraft measurements are spatially averaged instead of averaged over time (Crawford et al., 1993). The results hereafter are based on an averaging length of $2000 \mathrm{~m}$, which is at the lower range $(2000-4500 \mathrm{~m})$ that has been used before for heterogeneous surfaces (e.g. Desjardins et al., 1994; Ogunjemiyo et al., 2003; Gioli et al., 2004). The processing includes a stationarity test on each averaging window. The window is split in half and the average covariance of each window half $\overline{\operatorname{covar}\left(w, F_{h}\right)}$ needs to be between $0.3-1.7$ of the whole averaging window, $\operatorname{covar}(w, \bar{F})$, where $F$ can be any flux parameter and subscript $h$ is the index of a window half. For good reasons, this stationarity test marginally differs from conventions used for flux measurements at tower sites. While for flux data of tower sites $30 \mathrm{~min}$ of data is usually taken for this type of test (Aubinet et al., 2000), a $2000 \mathrm{~m}$ averaging window consists of only about $60 \mathrm{~s}$ of data. The shorter the sections of turbulence data compared to assess stationarity, the more likely it is they will differ due to stochastic variations in the data, and therefore, will be classified as nonstationary. Even with our relaxed criteria, we have found that using more than two sub-windows for our airborne data, the test would classify more than $50 \%$ of our length-averaged data as non-stationary. Another approach would have been to average fluxes over the full segment after some form of detrending, and then performing a stationarity test. We believe that both approaches in practice will give the same result as sequential short windows will follow and remove the same trend, albeit stepwise rather than continuous. In addition, in order to stay consistent with previous work by Gioli et al. (2004), we kept the current stationarity test for airborne data unchanged. Note that variations between windows integrated in the segments, which could also be interpreted as a form of non-stationarity, has explicitly been retained.

To derive regional fluxes, we have divided our flight tracks from both IOPs into segments, based on distinct landscape characteristics. Flight-path segmentation is based on geomorphic, soil and vegetation characteristics, using satellite imagery (a.o. Google Earth), a high-resolution elevation map (Farr et al., 2007), a 1-km resolution soil map with USDA texture classification (Fischer et al., 2008), and an enhanced 1-km resolution CORINE 2000 land-use map with 61 classes (Champeaux et al., 2005). As there are no specialized footprint models for airborne flux measurements available, the analytical footprint model by Hsieh et al. (2000) was chosen for performing simple footprint-length calculations, because it preforms sufficiently well under the convective conditions prevalent in both IOPs. The model, however, was not tested for measurement heights above $20 \mathrm{~m}$ (a.g.l.) and roughness lengths of more than $0.1 \mathrm{~m}$. The footprint model served as a tool to determine the upwind distance along which $90 \%$ of the surface flux originated from, and thus to identify the predominant land-use classes that govern the fluxes in the segments. For determining an average footprint-length, a roughness length $(0.35 \mathrm{~m})$ was chosen to represent the average summed roughness of the vegetation and its terrain in the flight domain. The calculations based on all $2000 \mathrm{~m}$ averaging windows from all flights show that the footprint extends between 3 and $6 \mathrm{~km}$ upwind of the flight track. 
Plotting all footprint areas for each $2 \mathrm{~km}$ window on top of each other revealed that the average footprint area is very much on both sides of the track for the periods under investigation. This is primarily due to the fact that during both IOPs winds were very light and variable in direction (see Sect. 2.2). For the same reasons, the horizontal displacement of the footprint can also be considered negligible, because low wind speeds keeps the area of maximum flux contribution close to the flight track. Since we retrieve average fluxes from more than one flight, thus, overlaying many different footprints, we assumed that accounting for this displacement was not necessary. Hence, we simplified our footprint analysis by neglecting the wind direction, and the average footprint length was used to determine the width on both sides along the flight track to extract data from the land-use map. The resulting "segment areas" as we will call them hereafter, have a 3-km overlap with adjacent segment areas (see Fig. 4). These segment areas should be good indicators of the area, influencing our segment fluxes (with no overlap) as we will see in Sect. 6.

Figure 5 shows that the area of all segments along our flight tracks (lower plot) represents the extracted flight domain (upper plot; box in Fig. 2) well, as both distributions of land-use classes are very similar to each other. For this comparison, only land-use data was extracted from the map for the areas of segments 3 till 12 , as only these segments have been flown in both IOP's and segment averaged flux data have been compiled for these (see below). As shown in the lower plot, the exact footprint length ( 3 or $6 \mathrm{~km}$ ) does not have a significant effect on the land-cover distribution. In this study, we use the more conservative footprint-length estimate of $3 \mathrm{~km}$. Differences between segment areas and extracted domain area larger than $2 \%$ are found in classes $\mathrm{MG}(+8.9 \%)$, WM $(-3.4 \%), \mathrm{VY}(+6.2 \%), \mathrm{FO}(-3.4 \%)$, and CCP/WC $(+3.0 \%)$. Except for classes VY and FO, these land-use classes with classes WC and CCP/SC dominate both the extracted domain area and the segments. Land-use classes that cover less than $10 \%$ have not been included in the analysis of our results. MG and WM are found in the river valley, and CCP, SC and WC in the hills. In some areas along the flight track, other land-use classes dominate, which are pastures (PA), bordelais vineyards (VY) and mixed forest (FO; not the official CORINE class), and consequently, these were put in their own segments. This resulted in 12 segments with varying lengths (on average $18 \mathrm{~km}$ ) as shown in Figs. 2 and 3, and as described in Table 2.

Next, measured data belonging to a particular segment was averaged for each flight passes as in formula (1):

$\bar{F}_{i, j}=\frac{\sum_{k=1}^{n} F_{i, j, k}}{n_{i, j}}$,

where $\bar{F}_{i, j}=$ average flux per flight pass $(j)$ per segment (i); $F_{i, j, k}=2$-km flux $(k)$ per flight pass per segment; and $n_{i, j}=$ number of $2-\mathrm{km}$ fluxes per flight pass per segment. This

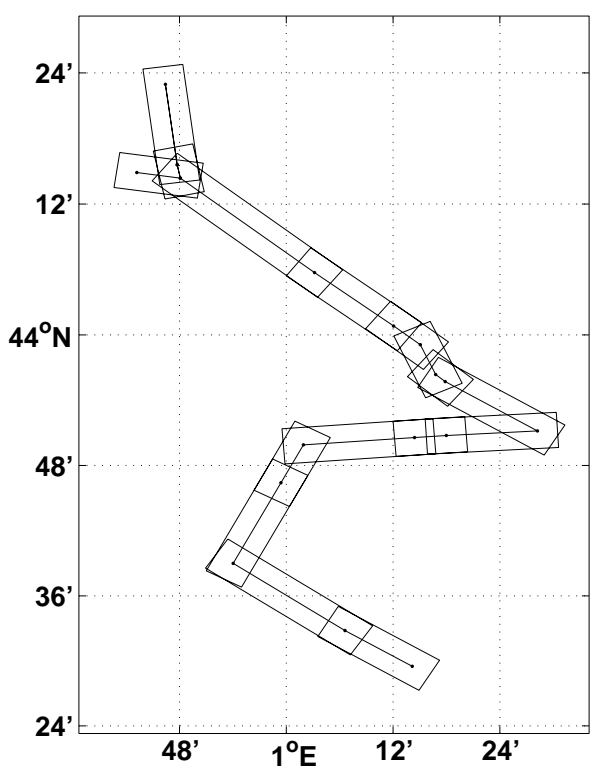

Fig. 4. Segment areas along two schematic flight tracks for extracting land-use information from land-use map (see Fig. 2) for segment 3 to 12 . Each area is build from its corresponding segment length (or sub-segment lengths with overlap removed) with a margin of $3 \mathrm{~km}$ all around it.

results in one average flux (e.g. one carbon-dioxide flux) for each segment per flight pass. Here, data in the terminal 2-km windows that partially overlapped with adjacent segments were retained.

Finally, all averaged data per segment have been once more averaged for all flight passes per IOP according to formula (2):

$\bar{F}_{i}=\frac{\sum_{j=1}^{m} \bar{F}_{i, j}}{m_{i}}$,

where $\bar{F}_{i}=$ averaged flux per segment $(i) ; \bar{F}_{i, j}=$ averaged flux per flight pass $(j)$ per segment $(i)$ resulting from formula (1); and $m_{i}=$ number of flight passes per segment. This results in one average flux for each segment per IOP. The corresponding error bars in our figures, are, therefore, the standard deviations that represent the variability between single passes.

To prevent the influence of diurnal variability on these averages (due to varying time of overflight at each location), we only selected flight data between 11:50 and 14:00 UTC (=LT-2). This implied that five outward flights between Villeneuve and Lamasquérè were selected from IOP 1 , and four return flights between Lamasquérè and Marmande from IOP 2. Thus, for IOP 1, the time of day progresses from segment 1 to the last segment, while for IOP 2, it is the opposite starting at segment 12 and ending at segment 1 . Due to this narrow time filter, no segment averages are available for segment 1 and 2 in IOP 1 , and for segments 1 to 3 in IOP 2.

To further reduce the effect of diurnal variability, we analysed heat fluxes indirectly as ratio's, since both the 
Table 2. Landscape characteristics of segments with 3-km width at both sides along flight tracks in the CERES experimental domain (See text for abbreviations). Land-use fractions of more than $10 \%$ are listed below.

\begin{tabular}{|c|c|c|c|c|c|}
\hline Segment & $\begin{array}{l}\text { Length } \\
\mathrm{km}\end{array}$ & $\begin{array}{l}\text { Extracted Area } \\
\mathrm{km}^{2}\end{array}$ & Terrain & Soil Type & $\begin{array}{l}\text { Land-Use (fraction } 3 \mathrm{~km} \text { ) } \\
\text { class }(\%)\end{array}$ \\
\hline 3 & 14 & 171 & hills NE & clay, loam & wm (34), ccp/sc (25), ccp/wc (13), pa (11) \\
\hline 4 & 34 & 348 & hills NE & clay, loam & $\mathrm{ccp} / \mathrm{wc}(41), \mathrm{ccp} / \mathrm{sc}(16), \mathrm{wm}(12)$, agr clusters $(12)$ \\
\hline 5 & 15 & 180 & river valley, river & loam & $\mathrm{mg}(35), \mathrm{ccp} / \mathrm{wc}(19), \mathrm{ccp} / \mathrm{sc}(14)$ \\
\hline 6 & 13 & 164 & river valley & loam & $\mathrm{mg}$ (27), ccp/wc (22), fo (15), ccp/sc (12), wm (10) \\
\hline 7 & 30 & 291 & river valley & loam & vy (43), mg (23), ccp/wc (14) \\
\hline 8 & 5 & 91 & river valley, river & loam & mg (45), vy (26), ccp/wc (15) \\
\hline 9 & 24 & 259 & hills SW & loam & mg (41), wc (31), wm (16) \\
\hline 10 & 16 & 182 & hills SW & clay & wc $(84)$ \\
\hline 11 & 20 & 229 & hills SW & clay & $\mathrm{wc}(81)$ \\
\hline 12 & 12 & 149 & river valley & clay, loam & mg (34), wc (21), ccp/wc (17), wm (17) \\
\hline
\end{tabular}
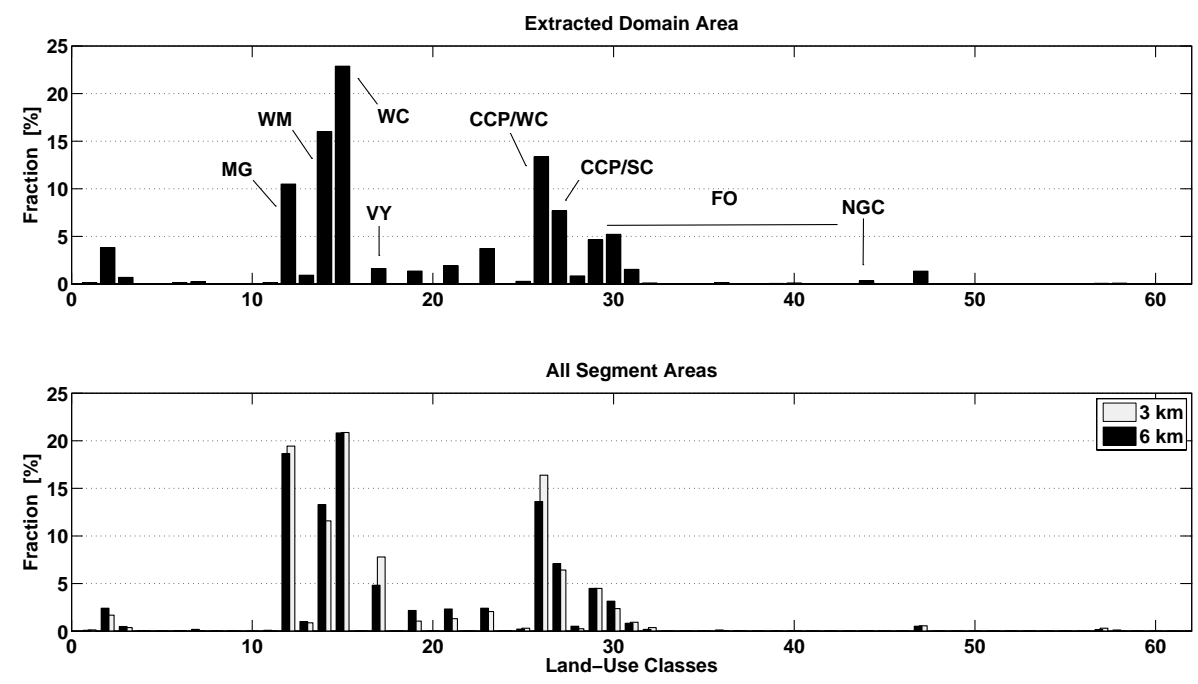

Fig. 5. Histogram of land-use classes for the extracted domain area (upper plot; see Fig. 2) and along flight track between segment 3 and 12 (lower plot) with 3-km and 6-km width at both sides at CERES'07 (See text for abbreviations).

evaporative fraction $\left(E_{f}=\lambda E /[\lambda E+H]\right)$ and the Bowen ratio $(\beta=H / \lambda E)$ are generally more conservative over a midday period than the absolute magnitude of the fluxes (Brutsaert, 2005; Crago and Brutsaert, 1996; Porporato, 2009).

\section{Results}

Due to the applied time filter on our data, this section presents the results belonging to segments 3 to 12 . Table 2 describes these segments with only those land-use classes that take up more than $10 \%$ of the segment area. It shows that class CCP/WC is the most wide-spread land use in the area (segments 3-8 and 12), but it is the third largest class in the area along the flight track (see lower plot in Fig. 5). In segment 4 , it is the predominant land-use class. Segment 4 is also the only segment containing the land-use class "Agricultural Clusters" and segment 3 is the only segment with class PA. Second most common land use along the track is class MG (segments 5-9 and 12). It is the predominant class in segments 5, 6, 8, 9 and 12. Class WC is the largest fraction in the area (see Fig. 5), but it is only found in segments 9, 10 and 11. The latter two have virtually only fields with winter crops. Segments 9 and 12 are rather similar in composition, but differ in fractions of winter crops represented as class WC and CCP/WC. The same is seen for segments 7 and 8 . Here, class "Bordelais Vineyards" (VY) is the predominant landuse class in segment 7 , while in segment 8 , it is the second largest after class MG. Class WM is found in segments 3, 4, 6, 9 and 12, and is the forth largest class along the flight track (see lower plot Fig. 5). Class CCP/SC is found in segments 3-6 with descending fractions. Finally, segment 6 is the most heterogeneous segment and it is the only one with class FO. 


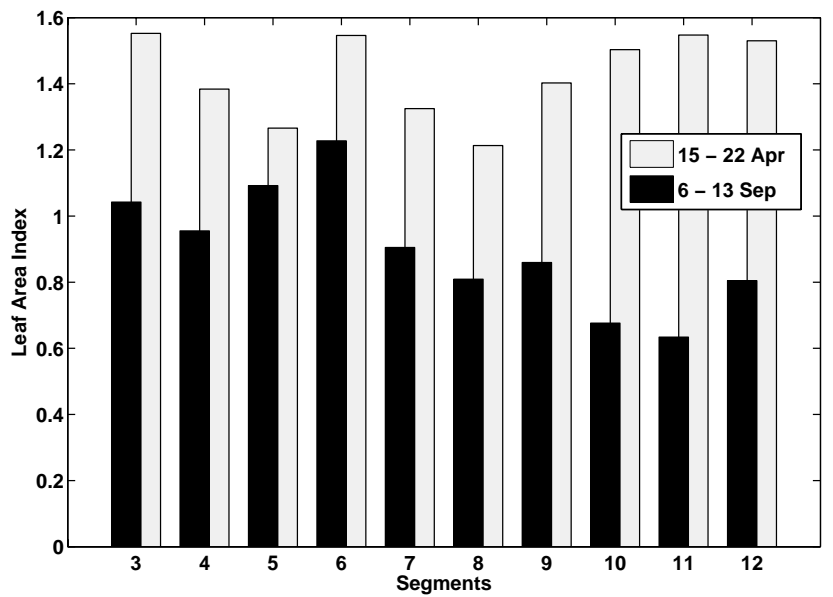

Fig. 6. Average leaf-area index per segment along flight track with $3 \mathrm{~km}$ width at both sides for 15-22 April and for 6-13 September from MODIS (8-day composite; $250 \mathrm{~m}$ resolution).

For the same segment areas, we retrieved an average leafarea index (LAI) from MODIS data of the Terra (EOS AM) satellite. Figure 6 shows the average LAI per segment for 15-22 April 2007 and for 6-13 September 2007. These time windows overlap with, respectively, IOP 1 and IOP 2. First, notice the clear difference in magnitude of LAI for both IOPs; April shows larger values than September when many crops were either harvested (winter wheat) or ripening and largely senescent (e.g. sun flowers). Secondly, during IOP 1, the LAI roughly decreases between segment 3 and 8 from about 1.6 to about 1.2 and after that increases again till about 1.5 with the exception of segment 6 and 7 with LAI of about 1.6 and 1.3, respectively. During IOP 2, it is more or less the opposite, starting at about 1.0 increasing till about 1.2 between segment 3 and 6 and down again to about 0.7 in the last segments. These spatial patterns reflect the dominance of late crops (e.g. maize) in the first few segments and that of winter crops in higher numbered segments.

Net radiation $\left(Q^{*}\right)$ and incoming photosynthetically active radiation $\left(\mathrm{PAR}_{i}\right)$ in the clear-sky conditions of our IOPs merely exhibit temporal - but no significant spatial - variations. Therefore, they are good indicators for the performance of our time filter. The average net radiation per segment for IOP 1 and IOP 2 are presented in Tables 3 and 4, respectively. During IOP 1 , the net radiation stays constant at about $550 \mathrm{~W} / \mathrm{m}^{2}$ between segments 3 and 6 and afterwards decreases somewhat gradually to about $470 \mathrm{~W} / \mathrm{m}^{2}$ in the last segment. During IOP 2, the net radiation is on average lower and has larger error bars (not presented here) than during IOP 1 . It increases between segment 4 to 10 from about 410 to about $450 \mathrm{~W} / \mathrm{m}^{2}$, and stays after that at about $430 \mathrm{~W} / \mathrm{m}^{2}$. The $\mathrm{PAR}_{i}$ (not shown here) shows for both periods somewhat the same, but less pronounced trend and change in error bars. During IOP $1, \mathrm{PAR}_{i}$ decreases from about 1720 to about
Table 3. Segment averages from airborne data along flight tracks during IOP 1 (18-22 April) at CERES'07.

\begin{tabular}{lccccc}
\hline Segment & LAI & $\begin{array}{c}f \mathrm{CO}_{2} \\
\mu \mathrm{mol} / \mathrm{m}^{2} / \mathrm{s}\end{array}$ & $\beta$ & $E_{f}$ & $\begin{array}{c}Q^{*} \\
\mathrm{~W} / \mathrm{m}^{2}\end{array}$ \\
\hline 3 & 1.55 & -11.2 & 0.65 & 0.61 & 564 \\
4 & 1.38 & -7.4 & 0.60 & 0.63 & 542 \\
5 & 1.27 & -3.4 & 0.54 & 0.65 & 541 \\
6 & 1.55 & -1.6 & 0.74 & 0.60 & 565 \\
7 & 1.32 & -3.0 & 0.40 & 0.72 & 534 \\
8 & 1.21 & -4.7 & 0.31 & 0.77 & 520 \\
9 & 1.40 & -6.9 & 0.47 & 0.69 & 503 \\
10 & 1.50 & -13.0 & 0.43 & 0.70 & 488 \\
11 & 1.55 & -13.4 & 0.40 & 0.72 & 486 \\
12 & 1.53 & -7.7 & 0.60 & 0.64 & 470 \\
\hline
\end{tabular}

Table 4. Same as Table 3, except during IOP 2 (7-14 September) at CERES'07.

\begin{tabular}{lccccc}
\hline Segment & LAI & $\begin{array}{c}f \mathrm{CO}_{2} \\
\mu \mathrm{mol} / \mathrm{m}^{2} / \mathrm{s}\end{array}$ & $\beta$ & $E_{f}$ & $\begin{array}{c}Q^{*} \\
\mathrm{~W} / \mathrm{m}^{2}\end{array}$ \\
\hline 3 & 1.04 & $\mathrm{n} / \mathrm{a}$ & $\mathrm{n} / \mathrm{a}$ & $\mathrm{n} / \mathrm{a}$ & $\mathrm{n} / \mathrm{a}$ \\
4 & 0.96 & -3.3 & 1.99 & 0.35 & 414 \\
5 & 1.09 & -4.1 & 1.31 & 0.44 & 436 \\
6 & 1.23 & -5.5 & 1.58 & 0.40 & 448 \\
7 & 0.91 & -4.4 & 1.78 & 0.37 & 448 \\
8 & 0.81 & -3.4 & 2.14 & 0.33 & 441 \\
9 & 0.86 & -5.8 & 1.86 & 0.36 & 456 \\
10 & 0.68 & -2.3 & 2.17 & 0.32 & 451 \\
11 & 0.63 & -0.7 & 2.10 & 0.33 & 425 \\
12 & 0.81 & -5.1 & 2.04 & 0.35 & 439 \\
\hline
\end{tabular}

$1400 \mu \mathrm{E} / \mathrm{m}^{2}$, while during IOP 2 , it stays somewhat constant at about $1370 \mu \mathrm{E} / \mathrm{m}^{2}$. As soil moisture is a limiting factor for photosynthesis and, consequently, for carbon-dioxide flux, the difference in $\mathrm{PAR}_{i}$ between both IOPs shows a clear link between the differences in the Bowen Ratio $(\beta)$, the Evaporative Fraction $\left(E_{f}\right)$ and the carbon-dioxide flux $\left(f \mathrm{CO}_{2}\right)$ presented in the following paragraphs. Both radiation parameters show some residual diurnal influence, which is opposite between both IOPs caused by the selected outward flights for IOP 1 and return flights for IOP 2 . We may conclude that the time filter worked well: light conditions were nearly identical during all flights (coefficient of variance $<10 \%$ ), though, minor temporal trends still need to be taken into account, when interpreting the segment averaged fluxes.

Figures 7 and 8 show for IOP 1 (April) and IOP 2 (September), segment averages of the Bowen ratio $\left([\bar{\beta}]_{\text {seg }}\right)$ and the evaporative fraction $\left(\left[\overline{E_{f}}\right]_{\text {seg }}\right)$, respectively. They show that $[\bar{\beta}]_{\text {seg }}$ is much lower during IOP 1 compared to IOP 2 . For $\left[\overline{E_{f}}\right]_{\text {seg }}$, it is the opposite, where IOP 2 is about $30 \%$ lower than IOP 1 . This corresponds with ground observations along the flight track as can be seen in Table 5. The results 

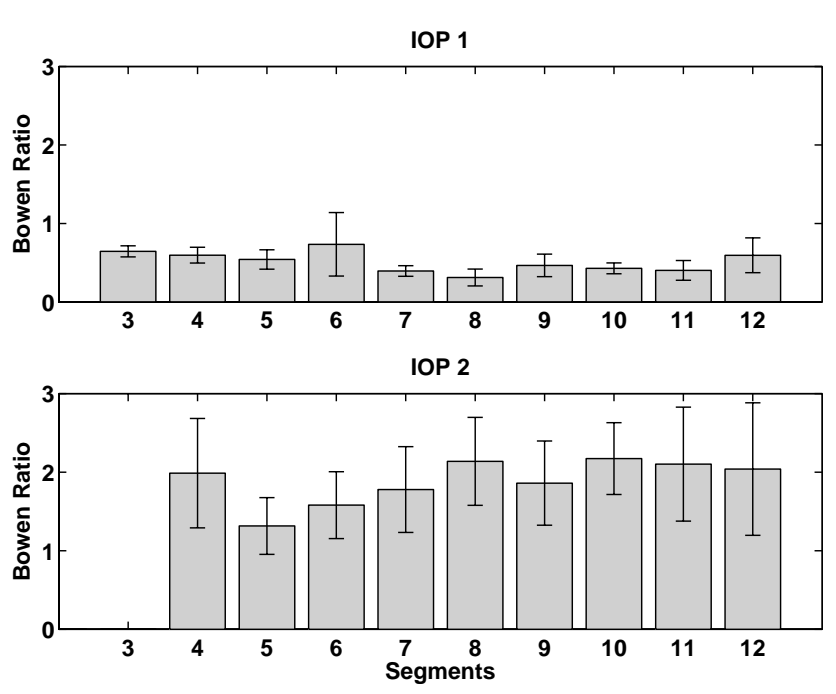

Fig. 7. Average Bowen ratio per segment with error bars (= standard deviation of single passes) along flight track during IOP 1 (1822 April) and IOP 2 (7-14 September) at CERES'07.

correspond with the amount of precipitation in the periods before the start of both IOPs, mentioned in Sect. 2.2. As these two ratios can be considered to be rather independent from the diurnal cycle, the variations in these fractions within each IOP are mostly related to the underlying landscape, while the differences between IOPs can be related to seasonal change.

Figures 9 and 10 show the average carbon-dioxide flux per segment $\left(\left[\overline{f \mathrm{CO}_{2}}\right]_{\text {seg }}\right)$, respectively, for IOP 1 and IOP 2 . The figures show that there was more carbon uptake during IOP 1 than during IOP 2, except for segment 5 to 7 , but also that the variability in carbon fluxes (error bars) was larger during IOP 1 compared to IOP 2 . This corresponds with the higher LAI and evaporative fractions found for IOP 1 as photosynthesis is coupled to plant transpiration and both are also a function of leaf area. The correlation is, however, not strong, because latent heat flux includes evaporation from soil and water bodies as well, and likewise, the carbon flux includes soil respiration. The larger carbon uptake during IOP 1 is consistent with the seasonal variation in crops as explained before for LAI. Looking at the differences between segments within each IOP, the carbon-dioxide flux for IOP 1 shows marked differences compared to IOP 2. During IOP 1 , the carbon uptake decreases between segments 3 to 6 from about -11 to about $-2 \mu \mathrm{mol} / \mathrm{m}^{2} / \mathrm{s}$ and afterwards increases again to more than $-13 \mu \mathrm{mol} / \mathrm{m}^{2} / \mathrm{s}$ in segments 10 and 11 , followed by a drop in the last segment to about $-8 \mu \mathrm{mol} / \mathrm{m}^{2} / \mathrm{s}$. As for IOP 2 , the carbon uptake increases between segments 4 and 6 from about -3 to about $-6 \mu \mathrm{mol} / \mathrm{m}^{2} / \mathrm{s}$, then decreases again in segment 11 to about $-1 \mu \mathrm{mol} / \mathrm{m}^{2} / \mathrm{s}$ with peak values in segments 9 and 12 of about -6 and $-5 \mu \mathrm{mol} / \mathrm{m}^{2} / \mathrm{s}$, respectively.
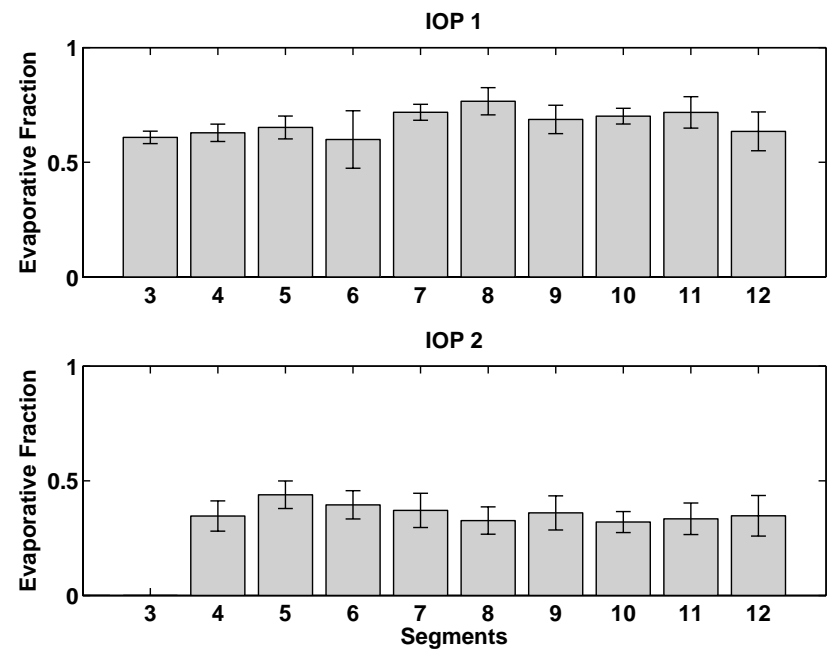

Fig. 8. Average evaporative fraction per segment with error bars (= standard deviation of single passes) along flight track during IOP 1 (18-22 April) and IOP 2 (7-14 September) at CERES'07.

The fluxes of some segments can be clearly related to their dominant land-use classes. First, segments 4, 10 and 11 contain winter crops as class WC or class CCP/WC. In April, winter crops were fully developed in this area, while in September, the same fields were bare. This is clearly represented by ground site "Lamasquérè" (LA), where during IOP 1, LA shows a high LAI, a large carbon uptake and a high evaporation, whereas during IOP 2 there was practically no carbon flux or evaporation from the then bare field (see Table 5). A similar change is found in our airborne carbon uptake ([ $\left.\left.\overline{f \mathrm{CO}_{2}}\right]_{\text {seg }}\right)$ of segments 4,10 and 11 in Tables 3 and 4. However, the change is more profound for segments 10 and 11 , because their areas consist for more than $80 \%$ of winter crops. Segment 4 is a complex, largely unknown mixture of land use, of which only part is winter crops in CCP/WC (see Table 2). This means that other types of land use within the segment may have resulted in still significant carbon uptake in IOP 2. For example, class WM and class CCP/SC are fully matured in September, which is shown for maize at station "Marmande" (MA) in Table 5. The leaf-area index for those segments supports this change between both periods (see Tables 3 and 4). Here, segments 10 and 11 have a larger decrease in LAI than segment 4 . Less obvious are the changes for $E_{f}$ and $\beta$ between the segments for both IOPs, although they agree with changes in LAI. The latter means bare fields in dry periods have a large $\beta$ and a small $E_{f}$. Bare soils lose their soil humidity in the top layer much quicker than when covered with vegetation, because on bare soils, water evaporates and runs through the soil more quickly. In the end, this results in a smaller $\lambda E$ and a larger $H$ as there is almost no water to evaporate. 
Table 5. Average data at ground sites between 11:50-14:00 UTC (=LT-2) during IOP 1 (18-22 April) and IOP 2 (7-14 September) at CERES'07.

\begin{tabular}{lccccc}
\hline Station & Vegetation & LAI & $\begin{array}{c}f \mathrm{CO}_{2} \\
\mu \mathrm{mol} / \mathrm{m}^{2} / \mathrm{s}\end{array}$ & $\beta$ & $E_{f}$ \\
\hline \multicolumn{7}{c}{ IOP 1} \\
\hline Marmande & maize & 0 & 3.3 & 2.88 & 0.26 \\
St. Sardos & grass & 3.9 & -23.2 & 0.26 & 0.79 \\
Auradé & sunflower & 0 & 0.3 & 0.78 & 0.56 \\
Lamasquérè & winter wheat & 4.3 & -33.6 & 0.08 & 0.92 \\
Le Fauga & fallow/grass & $\mathrm{n} / \mathrm{a}$ & -15.6 & 0.26 & 0.79 \\
\hline \multicolumn{7}{c}{$\mathrm{IOP} 2$} & & & \\
\hline Marmande & maize & $\approx 4$ & -20.3 & 0.84 & 0.54 \\
St. Sardos & grass & $\mathrm{n} / \mathrm{a}$ & -1.6 & 1.68 & 0.37 \\
Auradé & sunflower & 0 & 0.6 & 2.91 & 0.26 \\
Lamasquérè & winter wheat & 0 & -0.2 & 3.83 & 0.21 \\
Le Fauga & fallow/grass & $\mathrm{n} / \mathrm{a}$ & -2.4 & 4.39 & 0.19 \\
\hline
\end{tabular}

Secondly, segment 7 has more than $40 \%$ of vineyards and shows more carbon uptake in IOP 2 than in IOP 1 . This can be explained by the growth stage of the vineyards and class "Market Gardening". In April, these vineyards are still building up their leaves and grapes, whereas in September, they are fully matured. Measurements by CNRM at vineyard station "Fronton" (see Fig. 2) during the previous campaign (CERES'05) show that the LAI increases from 0.3 in April to 1.4 in mid-August. The LAI of the vineyards stays low due to their low soil coverage. However, our segment averaged LAI from MODIS data (see Tables 3 and 4) decreases from about 1.3 to 0.9 . This decrease can be explained by the presence of class CCP/WC which includes winter crops that are absent during September. The end result is a modest increase in carbon uptake. In contrast, segment 8 , which is similar to segment 7 in composition, shows a decrease in carbon uptake instead, but a similar change in LAI is found. In this segment, the fraction of class VY is almost half and the fraction of class MG is almost double compared to segment 7. This suggests that the type of "Market Gardening" that is found in these two segments might have additionally suppressed the increased carbon uptake of vineyards, but it is not clearly found in the change of LAI for both segments.

However, the early growth stage of vineyards in April and the complex structure of the remaining part of segments 7 and 8 has probably influenced the variability in the data (i.e. large error bars) during IOP 1 , compared to IOP 2 . Segment 8 is also the smallest segment with a length of $5 \mathrm{~km}$ and an area of $91 \mathrm{~km}^{2}$ (see Table 2). In other words, $\left[\overline{f \mathrm{CO}_{2}}\right]_{8}$ is to a larger extend affected by its neighbouring segments compared to the other segment averaged fluxes. As the segments have unequal lengths, the extend of influence of neighbouring segments differs for each segment. In this study, the carbon-dioxide fluxes are based on an averaging length of
$2 \mathrm{~km}$, which means that 2 or 3 length averaged fluxes fall within segment 8 for each flight pass. If, for a flight pass, segment 8 holds only two $2-\mathrm{km}$ fluxes, then those fluxes are calculated from raw data within segment 8 . However, if three 2-km fluxes fall within the segment, then one flux has partially been calculated from (maximum $1000 \mathrm{~m}$ of) raw data belonging to one of the neighbouring segments. This might be the reason that segment 8 shows the largest error bars during IOP 1.

More complex are all remaining segments (5, 6, 9 and 12) with class MG as their predominant land-use class. While segments 5 and 6 show an increase in carbon uptake, the other two show less uptake during IOP 2 compared to IOP 1. When trying to relate the fraction of MG to the changes of carbon uptake within each segment, no clear correlation appears. This is probably due to highly mixed and heterogeneous character of this land-use class. Class MG contains small scale winter and summer crops, but both can vary from segments to segment. Other land-use fractions and other factors may play a roll in these segments (see Table 2).

Segment 9 and 12 have a similar composition of major land-use fractions. They mainly differ in the fractions of MG and winter crops (i.e. CCP/WC and WC), where segment 9 does not have class CCP/WC. Although segment 9 has a larger fraction of only class WC, it shows a smaller reduction of carbon uptake (see Tables 3 and 4). The decrease of carbon uptake in segment 12 is about $3 \mu \mathrm{mol} / \mathrm{m}^{2} / \mathrm{s}$ in IOP 2 compared to IOP 1 , while in segment 9 , the decrease is only about $1 \mu \mathrm{mol} / \mathrm{m}^{2} / \mathrm{s}$. This difference in reduced carbon uptake corresponds with the segment averaged LAI in Tables 3 and 4 , where segment 12 shows a somewhat larger decrease than segment 9. Although $\beta$ and $E_{f}$ correspond with LAI, there is no significant difference between the two segments. The difference in reduced carbon uptake between the segments (about $2 \mu \mathrm{mol} / \mathrm{m}^{2} / \mathrm{s}$ ) might be partially explained, when assuming for segment 12 that, first, most of class CCP/WC are winter crops, and second, most crops in its class MG have been harvested by then as well. Unfortunately, ground sites "St. Sardos" (SS) in segment 9 and "Le Fauga" (LF) in segment 12 cannot be used as a reference due to the different land use on which they were installed.

Segment 6 shows the largest increase of carbon uptake of all segments (see Tables 3 and 4). In addition, it is the most complex segment with regard to the number of large land-use fractions $(>10 \%)$ as also indicated by the large error bars for both IOPs. During IOP 1 , it has the largest $\beta$, though, it still is less than 1.0, suggesting limited or no water stress. At the same time, the observed carbon flux is marginal (about $-2 \mu \mathrm{mol} / \mathrm{m}^{3} / \mathrm{s}$ ). During IOP 2 , it has the second lowest $\beta$, though, it is more than twice as high than during IOP 1. Combining these with the available energy shows absolute evaporation during IOP 2 is $>30 \%$ lower than in IOP 1 , suggesting considerable water stress. How that corresponds with one of the highest carbon uptake during this period, remains enigmatic. For both periods, it has one of the highest LAI 


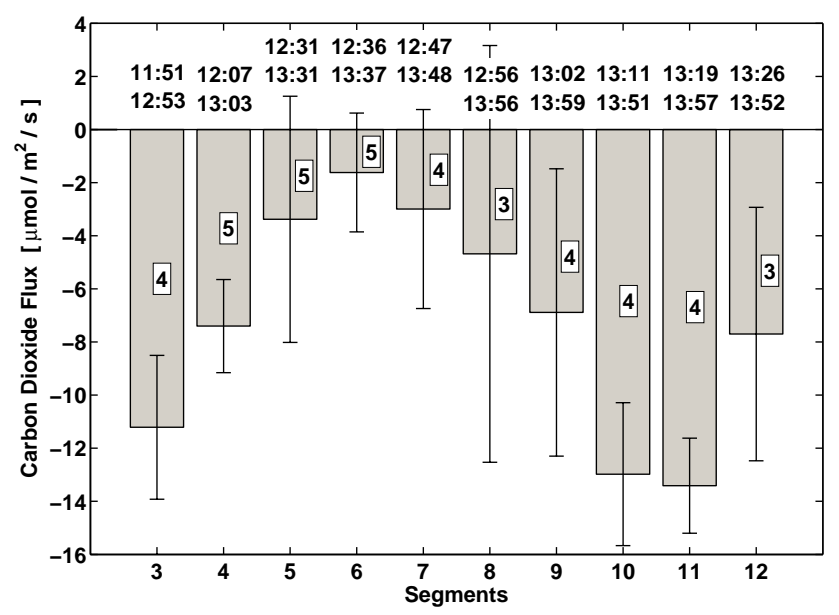

Fig. 9. Average carbon-dioxide flux per segment along flight track during IOP 1 (18-22 April) at CERES'07, where negative values mean carbon uptake. In addition, error bars (= standard deviation of single passes), time periods (UTC $=$ LT -2 ) and the amount of flights it is based upon (numbers in boxes) are depicted for each segment.

and the decrease in LAI is the second smallest of all segments. The large LAI with its small decrease, the significant decrease in evaporation and the increase in carbon uptake seem contradictory. Class FO, which includes among others coniferous trees, might be responsible for the large LAI during IOP 1 . On the other hand, the same class contains broad leave trees as well. This class, together with class WM and $\mathrm{CCP} / \mathrm{SC}$, might explain the large increase in carbon uptake. These classes account together for about $37 \%$ of the segment area, all containing vegetation that is fully matured during the summer season. The decrease in LAI due to the winter crops in other classes might have been compensated by these classes, including class FO.

Segment 5 is similar to segment 6 with the main difference that the former does not have class WM and class FO (see Table 2). Its carbon uptake shows a much smaller $\left(\sim 1 \mu \mathrm{mol} / \mathrm{m}^{3} / \mathrm{s}\right)$ increase than the increase seen for segment 6 $\left(\sim 4 \mu \mathrm{mol} / \mathrm{m}^{3} / \mathrm{s}\right)$. This corresponds with the LAI between both segments, where the LAI in segment 5 is smaller (1.0) than the one for segment 6 (1.2). In turn, $\beta$ and $E_{f}$ correlate with the changes in LAI between both IOPs, but the same contradiction exists here as for segment 6 . The carbon uptake in segment 5 shows the smallest change of all segments between both periods. The modest increase compared to segment 6 might be explained by the absence of class FO and $\mathrm{CCP} / \mathrm{SC}$, which have a higher carbon uptake in September.

\section{Discussion}

Overall, the airborne flux data seem to be consistent with the underlying terrain and to reflect true seasonal variations. Some methodological points of discussion still remain.

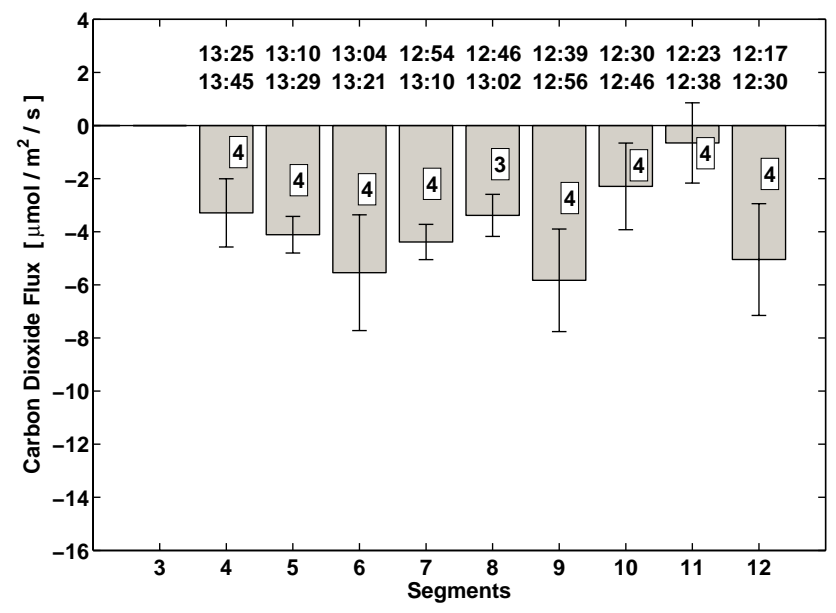

Fig. 10. Same as Fig. 9, except during IOP 2 (7-14 September) at CERES'07.

First, the raw data from a low flying aircraft like ours are influenced by changes in terrain elevation and the scale of surface heterogeneity. In particular, sharp transitions in terrain elevation seem to have a significant influence on the observed wind speed and direction, resulting in unstable fluxes for segments including such a transition. In our flight track, such a transition occurred between segment 4 and 5, when emerging from the hill area into a broad flat river valley. True outliers (i.e. erroneous data due to these effects) have been filtered out based on the stationarity and range checks, and though, error bars do not show exceptional magnitudes for these segments, some residual effects of these may still be present in the segment averaged fluxes.

In this respect, flying in non-ideal conditions, which makes constantly adjusting the flying altitude to the terrain height necessary, may induce a number of possible errors to the flux measurements. First, removal of aircraft motion may not be perfect with more than ideal vertical movements, even despite the careful calibration procedures we performed (Vellinga et al., 2010). Second, when flying at non-ideal pitch angles (e.g. flying uphill/downhill) potential flow theory is not fully valid. These two issues cannot be easily separated and may potentially be convoluted in some residual "up-wash effect", probably effective as rather low-frequency component. We attempted to analyse these for some the CERES flights from residual correlations between a.o. platform motion or pitch and observed vertical wind speed (like in Garman et al., 2006, 2008). However, the results were highly non-conclusive, and in our opinion, a dedicated experiment over hilly terrain but with highly homogeneous land cover, would be needed to progress on this. Moreover, our objective is not to have a perfect magnitude of $w$, like in disjunct or relaxed eddy-covariance methods, but instead we use the deviation from it $\left(w^{\prime}\right)$ in the covariance with scalars. By applying axis rotation, as we have done in our study, we rotate 
the system to force the mean $w$ to zero. This means that any bias in $w$ caused by either of the two issues does not reflect on our fluxes as we believe that they mostly propagate in the form of an offset in the absolute magnitude of $w$. Finally, a third error might be induced by vertical variations of flying altitude with respect to a (constant) scalar gradient of interest, that theoretically could lead to (small) overestimation of fluxes. Over flat terrain such errors appeared small $(+2$ to $+4 \%)$ in stable conditions to negligible $(+0.5 \%)$ in unstable conditions (Mahrt et al., 2005). In terrain-following flights, altitude variations with respect to the ground are probably larger than flying horizontally over flat terrain. At the same time, however, we can raise the question, whether the vertical gradients are horizontally constant over hilly terrain (probably not). Analysing this problem requires dedicated experiments beyond the scope of the present study. Here, we assume errors of this type are of positive sign, but probably negligibly small.

A correlation between flight direction and measured wind direction might be induced by limited frequency response of the sensors in relation to the possibly higher apparent turbulence frequencies flying into the wind as compared to when flying downwind (Desjardins et al., 1989). Thus, high frequency loss would be higher into the wind than downwind. The resultant systematic error in wind direction might, for instance, affect the position of the individual footprints. Visual checks of our data assured us that flight direction (i.e. outward against return flight) did not significantly affect the measured wind direction. Also, compared to Desjardins et al. (1989), we used faster sensors sampled at higher frequencies $(50 \mathrm{~Hz})$ and we flew at lower airspeed, reducing overall high-frequency loss. In addition, we flew in very calm conditions with wind speeds lower than those encountered by Desjardins et al. (1989), further reducing differences in high frequency-loss as a function of the angle between flight and wind direction.

Secondly, the length of the averaging window of $2000 \mathrm{~m}$, we use in this study, is at the lower end of the range generally used. The selection process for the optimal averaging length is always a compromise between resolving the scale of heterogeneous surface and including the main fraction of (i.e. the largest) turbulent eddies (LeMone et al., 2003). We assume that the subsequent averaging of fluxes into larger segments largely compensates for our rather small averaging windows. In this study, the smallest segment is about $5 \mathrm{~km}$ (see Table 2), which should be long enough to resolve the largest fraction of turbulent eddies within this segment (Lyons et al., 2001; LeMone et al., 2003) when at least two $2-\mathrm{km}$ averaged fluxes are available. However, we have used filters on our 2-km window averaged fluxes to remove spikes, which may have removed some "true" flux transported by large eddies.

Third, the reconstruction of the footprint area influencing our measurements is very basic. In this study, footprintlength calculations are based on one of many models (e.g. Schmid, 2002), which uses here a constant roughness length $\left(z_{0}\right)$ for the whole flight domain. An average roughness length per segment based on the land-use classes within the segment and accounting for stability effects using observed heat fluxes, could alternatively have been used to determine the footprint length per segment. Also, footprint areas are usually weighted with a Gaussian weight distribution with a strong positive skewness parallel to the wind direction. The land-use classes in our segments were not weighted in this way. Our method resulted in so-called "segment areas" based on averaged, first-order estimates of footprint length followed by an analysis of the land use in each segment area. In our analysis, using a double footprint area (i.e. $6 \mathrm{~km}$ on either side of the flight track instead of $3 \mathrm{~km}$ ) did not significantly change the land-cover class distributions or characteristics, like LAI, justifying our choice for the simple and more conservative approach.

Finally, the influence of diurnal variations on segment averages has been minimized by selecting only data obtained between 11:50 and 14:00 UTC. However, some small degree of diurnal effect remains as illustrated by the segment averaged $Q^{*}$ in Tables 3 and 4 . Within this time window, the flight track during IOP 1 was flown in opposite direction compared to IOP 2. Nevertheless, given that the total coefficient of variation of $Q^{*}$ is less than $10 \%$, we believe this effect did not significantly influence our results.

To investigate the extend to which our airborne data compare with the ground data, we need to upscale the ground data to regional scale since a direct comparison between airborne data and ground data is not possible (Mahrt, 1998; Gioli et al., 2004). In principle, the distribution of land-use fractions along the flight tracks (see Fig. 5) can be used together with ground-based flux magnitudes to do this. Table 5 shows that the ground sites provide data for land-use classes SC, WM, WC and "Natural Grasslands Cluster" (NGC), while data on the largest class MG is missing. For classes CCP/SC and $\mathrm{CCP} / \mathrm{WC}$, the fraction of $\mathrm{SC}$ and $\mathrm{WC}$ needs to be estimated. When assuming that $2 / 3$ of classes CCP/SC and $\mathrm{CCP} / \mathrm{WC}$ is $\mathrm{WC}$ and $\mathrm{SC}$, the available ground data covers only about $45 \%$ of the whole area along the flight tracks. In addition, with regard to the used land-use map, Sarrat et al. (2009a) found that land-use classes WM and WC are underestimated and overestimated by about $40 \%$, respectively. This was confirmed by our visual inspections during the flights, which also indicated more maize on the ground than the land-use map suggests. Filling the gap for the missing classes by numerical modelling of fluxes from vegetation would further introduce more complexity to the results. The uncertainties with respect to the land cover in the area, combined with still fragmentary ground data made us refrain from a pure data-based upscaling.

Finally, as the land-use distribution of the extracted part along the flight track does not considerably differ from the one of the whole flight domain (see Fig. 5), we can get a good idea about the carbon uptake for the whole flight domain 
(see box in Fig. 2) by determining the weighted average carbon uptake of all segments (see Table 2). This shows that the average carbon-dioxide flux for IOP 1 (April) is about $-7 \mu \mathrm{mol} / \mathrm{m}^{2} / \mathrm{s}$, which is larger than IOP 2 (September) with an average of about $-4 \mu \mathrm{mol} / \mathrm{m}^{2} / \mathrm{s}$. These appear to be of low magnitude compared to other studies. For instance, Gibert et al. (2007) found much higher uptakes $\left(-20 \mu \mathrm{mol} / \mathrm{m}^{2} / \mathrm{s}\right)$ for a region dominated by winter crops in May, and Schmitgen et al. (2004) found a regional flux of $-16 \mu \mathrm{mol} / \mathrm{m}^{2} / \mathrm{s}$ for the area just to the north-west of our region in June. Likewise, based on inversion studies, Sarrat et al. (2009b) found for the same area and season as Schmitgen et al. (2004) regional fluxes varying between -10 and $-16 \mu \mathrm{mol} / \mathrm{m}^{2} / \mathrm{s}$. Based on upscaling of ground fluxes, Sarrat et al. (2009b) found regional fluxes between -9 and $-12 \mu \mathrm{mol} / \mathrm{m}^{2} / \mathrm{s}$. The last 5 numbers are exemplary of the present day uncertainty still associated with determining regional carbon dioxide fluxes. Though, representing a slightly different area, our estimates seem to broaden the uncertainty range rather than limit it.

\section{Conclusions}

The main goal of this study is to find a method for retrieving regional fluxes from an airborne data-set of the field experiment CERES'07 for investigating temporal and spatial variations in the fluxes linked to the underlying heterogeneous landscape. Focus has been on the carbon uptake during two IOPs at CERES'07. Our method consists of flight-path segmentation based on homogeneous landscape characteristics. The carbon uptake can generally be related in a meaningful way to seasonal trends and variations in land use. The landuse distribution of the extracted part along the flight track does not considerably differ from the one of the whole flight domain (see Fig. 5).

The carbon uptake correlates well with the leaf-area index from MODIS between the segments and between the IOPs. In particular, the contrast between segments with predominantly winter crops and other segments is clearly visible. The energy fluxes support the seasonal change in carbon uptake and leaf-area index, but do not clearly show differences between the segments within an IOP. Scaling up the results to the total area of all segments shows an average Bowen ratio of 0.49 in April (IOP 1) or an evaporative fraction of 0.67 . In September (IOP 2), they are $\beta=1.77$ and $E_{f}=0.36$. The carbon and energy fluxes, though consistent with data from ground stations, cannot be quantitatively compared, because ground data were incomplete with regard to the land-cover classes covered and because of uncertainties in the landcover map. Instead, we believe that airborne fluxes averaged and segmented in relation to variability at the landscape scale are in themselves very useful to quantify regional fluxes for energy and carbon dioxide in a direct way. Regional estimates that can be used as a reference for other estimates, whether they are based on inverse methods from, for exam- ple, tall tower measurements or model based on, for instance, remote-sensing derived vegetation characteristics.

Acknowledgements. This study was jointly supported by the European Framework Programme 6 Integrated Project CarboEurope (GOCE-CT2003-505572), by the Dutch national research programme "Climate changes Spatial Planning" (www.climatechangesspatialplanning.nl), and by the Strategic Knowledge Development Programme of Wageningen UR on Climate Change (Kennisbasis thema Klimaatverandering) funded by the Dutch ministry of Agriculture, Nature and Food Quality. We thank our pilots of the Aero Company Vliegschool Teuge BV (ACVT, Netherlands) for their careful, terrain hugging flight manoeuvres. Many thanks go to Franco Miglietta at IBIMET-CNR and to Edward J. Dumas at ARL-NOAA for their highly appreciated support in developing the processing software. For this, a working visit at IBIMET-CNR was funded by the Netherlands Organisation of Scientific Research (NWO). In addition, many thanks go to Jordi Vila-Guerau de Arellano, and Ronald J. Dobosy and the anonymous reviewer for carefully reading the manuscript and providing useful advice in improving it. Last but not least, thanks go to all colleagues of the CarboEurope-IP Regional Experiment for the pleasant collaboration during the field campaigns.

Edited by: T. Laurila

\section{References}

André, J., Goutorbe, J., and Perrier, A.: HAPEX-MOBILHY: A hydrologic atmospheric experiment for the study of water-budget and evaporation flux at the climatic scale, B. Am. Meteorol. Soc., 67, 138-144, 1986.

Andreae, M. O., Artaxo, P., Fischer, H., Freitas, S. R., Grégoire, J. M., Hansel, A., Hoor, P., Kormann, R., Krejci, R., Lange, L., Lelieveld, J., Lindinger, W., Longo, K., Peters, W., de Reus, M., Scheeren, B., Silva Dias, M. A. F., Ström, J., van Velthoven, P. F. J., and Williams, J.: Transport of Biomass Burning Smoke to the Upper Troposphere by Deep Convection in the Equatorial Region, Geophys. Res. Lett., 28, 951-954, 2001.

Aubinet, M., Grelle, A., Ibrom, A., Rannik, U., Moncrieff, J., Foken, T., Kowalski, A. S., Martin, P. H., Berbigier, P., Bernhofer, C., Clement, R., Elbers, J., Granier, A., Grunwald, T., Morgenstern, K., Pilegaard, K., Rebmann, C., Snijders, W., Valentini, R., and Vesala, T.: Estimates of the annual net carbon and water exchange of forests: The EUROFLUX methodology, Adv. Ecol. Res., 30, 113-175, 2000.

Brutsaert, W.: Hydrology: An Introduction, Cambridge University Press, 2005.

Champeaux, J.-L., Fortin, H., and Han, K.-S.: SpatioTemporal Characterization of Biomes over SW of France using SPOT/VEGETATION and CORINE Land Cover Datasets, in: Geoscience and Remote Sensing Symposium, 2005. IGARSS'05. Proceedings, 2005 IEEE International, vol. 2, 1295-1298, 2005.

Claussen, M.: Area-averaging of surface fluxes in a neutrally stratified, horizontally inhomogeneous atmospheric boundary layer, Atmos. Environ., 24A, 1349-1360, 1990. 
Crago, R. and Brutsaert, W.: Daytime evaporation and the selfpreservation of the evaporative fraction and the Bowen ratio, J. Hydrol., 178, 241-255, 1996.

Crawford, T. L., McMillen, R. T., Dobosy, R. J., and MacPherson, I.: Correcting airborne flux measurements for aircraft speed variation, Bound.-Lay. Meteorol., 66, 237-245, 1993.

Denning, A. S., Takahashi, T., and Friedlingstein, P.: Can a strong atmospheric $\mathrm{CO} 2$ rectifier effect be reconciled with a "reasonable" carbon budget?, Tellus B, 51, 249-253, 1999.

Desjardins, R. L., MacPherson, J. I., Schuepp, P. H., and Karanja, F.: An evaluation of aircraft flux measurements of $\mathrm{CO} 2$, water vapor and sensible heat, Bound.-Lay. Meteorol., 47, 55-69, 1989.

Desjardins, R. L., Hart, R. L., Macpherson, J. I., Schuepp, P. H., and Verma, S. B.: Aircraft-Based and Tower-Based Fluxes of Carbon-Dioxide, Latent, and Sensible Heat, J. Geophys. Res.Atmos., 97, 18477-18485, 1992.

Desjardins, R. L., MacPherson, J. I., Schuepp, P. H., and Hayhoe, H. N.: Airborne flux measurements of $\mathrm{CO} 2$, sensible, and latent heat over the Hudson Bay lowland, J. Geophys. Res., 99, 1551$1561,1994$.

Dolman, A. J., Noilhan, J., Durand, P., Sarrat, C., Brut, A., Piguet, B., Butet, A., Jarosz, N., Brunet, Y., Loustau, D., Lamaud, E., Tolk, L., Ronda, R., Miglietta, F., Gioli, B., Magliulo, V., Esposito, M., Gerbig, C., Körner, S., Glademard, P., Ramonet, M., Ciais, P., Neininger, B., Hutjes, R. W. A., Elbers, J. A., Macatangay, R., Schrems, O., Pérez-Landa, G., Sanz, M. J., Scholz, Y., Facon, G., Ceschia, E., and Beziat, P.: The CarboEurope Regional Experiment Strategy, B. Am. Meteorol. Soc., 87, 13671379, 2006.

Dolman, A. J., Gerbig, C., Noilhan, J., Sarrat, C., and Miglietta, F.: Detecting regional variability in sources and sinks of carbon dioxide: a synthesis, Biogeosciences, 6, 1015-1026, 2009, http://www.biogeosciences.net/6/1015/2009/.

Dumas, E., Brooks, S., and Verfaillie, J.: Development and Testing of a Sky Arrow 650 ERA Aircraft for Atmospheric Research, in: 11th Symposium on Meteorological Observations and Instrumentation (14-18 January 2001 Albuquerque, New Mexico) Near Fine, American Meteorological Society's 81st Annual Meeting, American Meteorological Society, Kuenzig Books, Albuquerque (NM), USA, 2001.

Eckman, R., Crawford, T., Dumas, E., and Birdwell, K.: Airborne Meteorological Measurements Collected During The Model Validation Program (Mvp) Field Experiments At Cape Canaveral, Florida, Technical Memorandum ARL/ATDD-233, NOAA/ARL, Silver Spring (Maryland), USA, 1999.

Farr, T., Rosen, P., Caro, E., Crippen, R., Duren, R., Hensley, S., Kobrick, M., Paller, M., Rodriguez, E., Roth, L., Seal, D., Shaffer, S., Shimada, J., Umland, J., Werner, M., Oskin, M., Burbank, D., and Alsdorf, D.: The shuttle radar topography mission, Rev. Geophys., 45, RG2004, doi:10.1029/2005RG000183, 2007.

Fischer, G., Nachtergaele, F., Prieler, S., van Velthuizen, H., Verelst, L., and Wiberg, D.: Global Agro-ecological Zones Assessment for Agriculture (GAEZ 2008), http://www.iiasa.ac.at/Research/ LUC/luc07/External-World-soil-database/, 2008.

Garman, K. E., Hill, K. A., Wyss, P., Carlsen, M., Zimmerman, J. R., Stirm, B. H., Carney, T. Q., Santini, R., and Shepson, P. B.: An airborne and wind tunnel evaluation of a wind turbulence measurement system for aircraft-based flux measurements,
J. Atmos. Ocean. Tech., 23, 1696-1708, 2006.

Garman, K. E., Wyss, P., Carlsen, M., Zimmerman, J. R., Stirm, B. H., Carney, T. Q., Santini, R., and Shepson, P. B.: The Contribution of Variability of Lift-induced Upwash to the Uncertainty in Vertical Winds Determined from an Aircraft Platform, Bound.-Lay. Meteorol., 126, 461-476, 2008.

Gerbig, C., Lin, J. C., Wofsy, S. C., Daube, B. C., Andrews, A. E., Stephens, B. B., Bakwin, P. S., and Grainger, C. A.: Toward constraining regional-scale fluxes of $\mathrm{CO} 2$ with atmospheric observations over a continent: 2 . Analysis of COBRA data using a receptor-oriented framework, J. Geophys. Res.-Atmos., 108, 119,2003

Gibert, F., Schmidt, M., Cuesta, J., Ciais, P., Ramonet, M., Xueref, I., Larmanou, E., and Flamant, P.-H.: Retrieval of average CO2 fluxes by combining in situ $\mathrm{CO} 2$ measurements and backscatter lidar information, J. Geophys. Res., 112, 1-16, 2007.

Gioli, B., Miglietta, F., De Martino, B., Hutjes, R. W. A., Dolman, H. A. J., Lindroth, A., Schumacher, M., Sanz, M. J., Manca, G., Peressotti, A., and Dumas, E. J.: Comparison between tower and aircraft-based eddy covariance fluxes in five European regions, Agr. Forest Meteorol., 127, 1-16, 2004.

Gioli, B., Miglietta, F., Vaccari, F. P., Zaldei, A., and De Martino, B.: The Sky Arrow ERA, an innovative airborne platform to monitor mass, momentum and energy exchange of ecosystems, Annals of Geophysics, 49, 109-116, 2006.

Hacker, J. M. and Crawford, T. L.: The BAT-Probe: The ultimate tool to measure turbulence from any kind of aircraft (or sailplane), Technical Soaring, 23, 42-45, 1999.

Hall, F. G.: Introduction to special section: BOREAS III, J. Geophys. Res.-Atmos., 106, 33511-33516, 2001.

Hsieh, C. I., Katul, G., and Chi, T.: An approximate analytical model for footprint estimation of scaler fluxes in thermally stratified atmospheric flows, Adv. Water Res., 23, 765-772, 2000.

Hutjes, R., Van den Bulk, W., Cosin, S., Erisman, J., Fritsch, H., Gioli, B., Grelle, A., Hensen, A., Lagergren, F., Lindroth, A., Ter Maat, H., Mantilla, E., Miglietta, F., Millán, M., Mölder, M., Ouden, A. d., Pérez, G., Ronda, R., Sanz, M., Schmitgen, S., Schumacher, M., Tuulik, J., Vermeulen, A., and Vilà-Guerau de Arellano, J.: Regional Assessment and Monitoring of the Carbon Balance within Europe (RECAB), Tech. Rep. EVK2-CT-199900034, Wageningen UR, Alterra, 2003.

Hutjes, R., Vellinga, O., Gioli, B., and Miglietta, F.: Disaggregation of airborne flux measurements using footprint analysis, Agr. Forest Meteorol., doi:10.1016/j.agrformet.2010.03.004, in press, 2010.

Kirby, S., Dobosy, R., Williamson, D., and Dumas, E.: An aircraftbased data analysis method for discerning individual fluxes in a heterogeneous agricultural landscape, Agr. Forest Meteorol., 148, 481-489, 2008.

LeMone, M. A., Grossman, R. L., Chen, F., Ikeda, K., and Yates, D.: Choosing the Averaging Interval for Comparison of Observed and Modeled Fluxes along Aircraft Transects over a Heterogeneous Surface, J. Hydrometeorol., 4, 179-195, 2003.

Lyons, T. J., Fuqin, L., Hacker, J. M., Cheng, W.-L., and Xinmei, H.: Regional turbulent statistics over contrasting natural surfaces, Meteorol. Atmos. Phys., 78, 183-194, 2001.

Mahrt, L.: Flux sampling errors for aircraft and towers, J. Atmos. Ocean. Techn., 15, 416-429, 1998.

Mahrt, L., Vickers, D., Drennan, W. M., Graber, H. C., and Craw- 
ford, T. L.: Displacement Measurement Errors from Moving Platforms, J. Atmos. Ocean. Tech., 22, 860-868, 2005.

Mann, J. and Lenschow, D. H.: Errors in airborne flux measurements, Journal of Geophys. Res.-Atmos., 99, 14519-14526, 1994.

Ogunjemiyo, S. O., Kaharabata, S. K., Schuepp, P. H., MacPherson, I. J., Desjardins, R. L., and Roberts, D. A.: Methods of estimating $\mathrm{CO}_{2}$, latent heat and sensible heat fluxes from estimates of land cover fractions in the flux footprint, Agr. Forest Meteorol., 117, 125-144, 2003.

Pérez-Landa, G., Ciais, P., Sanz, M. J., Gioli, B., Miglietta, F., Palau, J. L., Gangoiti, G., and Millán, M. M.: Mesoscale circulations over complex terrain in the Valencia coastal region, Spain Part 1: Simulation of diurnal circulation regimes, Atmos. Chem. Phys., 7, 1835-1849, 2007, http://www.atmos-chem-phys.net/7/1835/2007/.

Peters, W., Jacobson, A. R., Sweeney, C., Andrews, A. E., Conway, T. J., Masarie, K., Miller, J. B., Bruhwiler, L. M. P., Pétron, G., Hirsch, A. I., Worthy, D. E. J., van der Werf, G. R., Randerson, J. T., Wennberg, P. O., Krol, M. C., and Tans, P. P.: An atmospheric perspective on North American carbon dioxide exchange: CarbonTracker, P. Natl. Acad. Sci., 104, 18925-18930, 2007.

Porporato, A.: Atmospheric Boundary-Layer Dynamics with Constant Bowen Ratio, Bound.-Lay. Meteorol., 132, 227-240, 2009.

Sarrat, C., Noilhan, J., Lacarrère, P., Ceschia, E., Ciais, P., Dolman, A. J., Elbers, J. A., Gerbig, C., Gioli, B., Lauvaux, T., Miglietta, F., Neininger, B., Ramonet, M., Vellinga, O., and Bonnefond, J. M.: Mesoscale modelling of the $\mathrm{CO}_{2}$ interactions between the surface and the atmosphere applied to the April 2007 CERES field experiment, Biogeosciences, 6, 633-646, 2009a.
Sarrat, C., Noilhan, J., Lacarrre, P., Masson, V., Ceschia, E., Ciais, P., Dolman, A., Elbers, J., Gerbig, C., and Jarosz, N.: $\mathrm{CO}_{2}$ budgeting at the regional scale using a Lagrangian experimental strategy and meso-scale modeling, Biogeosciences, 6, 113-127, 2009b.

Schmid, H. P.: Footprint modeling for vegetation atmosphere exchange studies: a review and perspective, Agr. Forest Meteorol., 113, 159-183, 2002.

Schmitgen, S., Geiss, H., Ciais, P., Neininger, B., Brunet, Y., Reichstein, M., Kley, D., and Volz-Thomas, A.: Carbon dioxide uptake of a forested region in southwest France derived from airborne $\mathrm{CO} 2$ and $\mathrm{CO}$ measurements in a quasi-Lagrangian experiment, J. Geophys. Res.-Atmos., 109, 1-15, 2004.

Sellers, P. J., Hall, F. G., Asrar, G., Strebel, D. E., and Murphy, R. E.: The first ISLSCP field experiment (FIFE), B. Am. Meteorol. Soc., 69, 22-27, 1988.

Vellinga, O. S., Hutjes, R. W. A., Gioli, B., et al.: Calibration and data-processing of a mobile flux platform on a small environmental research aircraft, in preparation, 2010.

Vila-Guerau de Arellano, J., Gioli, B., Miglietta, F., Jonker, H. J. J., Baltink, H. K., Hutjes, R. W. A., and Holtslag, A. A. M.: Entrainment process of carbon dioxide in the atmospheric boundary layer, J. Geophys. Res.-Atmos., 109, 1-15, 2004.

Wood, N. and Mason, P.: The Influence Of Static Stability On The Effective Roughness Lengths For Momentum And HeatTransfer, Q. J. Roy. Meteorol. Soc., 117, 1025-1056, 1991. 